International Journal of Engineering \& Technology, $7(4.37)(2018) 211-213$
International Journal of Engineering \& Technology
SPC
Website: www.sciencepubco.com/Index.Php/IJET
Research Paper

\title{
Investigating the Behavior of Concrete and Mortar Reinforced with Aluminum Waste Strips
}

\author{
Rawa Shakir Muwashee ${ }^{1 *}$, Hamid Athab Al-Jameel ${ }^{2}$, Qusay Abdulhameed Jabal ${ }^{3}$ \\ 1,2,3 University of Kufa, Faculty of Engineering, Najaf, Iraq \\ *Corresponding author E-mail: rawas.muwashee@uokufa.edu.iq
}

\begin{abstract}
Composite concrete such as fiber reinforced concrete is widely used in structures because of its excellent properties such as compressive, flexural and tensile strengths and also high modulus of elasticity because it gives lower strain values under loading and too fewer cracks propagation. In this study, Aluminum strips was prepared by cutting the Coca- Cola cans as strips in concrete. The reason of using Aluminum strip is low density and good tensile strength (about $310 \mathrm{MPa}$ ) and also has a good ductility. The results of this study show good improvements in compressive, tensile and flexural strengths using 117 tested specimens for both concrete and mortar. In brief, about $22 \%$ increment in compressive strength of Aluminum strip concrete and flexural strength increases from 3.31 MPa to $11.20 \mathrm{MPa}$ when using Aluminum strips with $2.5 \%$ by volume of concrete. The reinforced mortar with Aluminum strips demonstrates significant increments which are $27 \%$ for compressive strength and more than $100 \%$ for both flexural and tensile strengths comparing with reference mix.
\end{abstract}

Keywords: Compressive strength, ductility, flexural strength, strips reinforced concrete, Aluminum strips.

\section{Introduction}

Before approximately five decades, the concept of composite materials such as fiber reinforced concrete, steel, glass and synthetic fibers such as polypropylene fibers was one topic of interest $\mathrm{Mu}-$ rali et al., 2012). Generally, concrete is weak in tensile strength and strong in compressive strength. Therefore, the main aim of concrete technology is to strengthen the tensile in concrete using different composite materials such as fiber. Moreover, waste tins of coca cola reaches up to one million tons every year which creates environmental problem (WRAP, 2010). Hence, this study has focused on using waste Coca-Cola strips in concrete to improve the mechanical properties of concrete.

\section{Previous Studies}

Composite concrete such as fiber reinforced concrete or glass is widely used in different structures such as aircraft parking, Fiber Reinforced Concrete (FRC) slabs and rigid pavements(Wafa, 1990). This could be attributed that the plain concrete is a brittle material with very low tensile strength and very low or no ductility. Therefore, using fibers can make concrete resist to deformations without cracks or very less cracks compared with normal concrete (Milind, 2016). Furthermore, fibers can give higher ductility and toughness to concrete and increase compressive, tensile and flexural strengths. Consequently, this makes concrete more durable, low maintenance cost and high load resistance (Milind, 2016).

Murali et al., (2012) used four waste materials (lathe waste, soft drink bottle caps, empty waste tins and waste steel powder from workshop) in concrete at a dosage of $1 \%$ of total weight of concrete as fibers. The results show that adding steel powder increases the compressive strength of $41.25 \%$ more than conventional concrete. Whereas, split tensile strength has increased up to $40.87 \%$. In addition, the flexural strength increases by $25.88 \%$ when adding soft drink bottle caps as waste material. In summary, the authors used one mix proportion and just three tests which are compressive strength, split tensile strength and flexural strength. Ravinder (2016) conducted experimental work on the use of CocaCola tin waste as fiber in concrete to improve the mechanical characteristic of concrete. The percentages of this fiber were $0 \%$, $0.5 \%, 1.0 \%$ and $1.5 \%$ by the volume of concrete with $1: 1.5: 3$ nominal concrete mix. The results show that a percentage of fiber increases from $0 \%$ to $1.5 \%$, the compression strength decreases from 41.6 to $38.0 \mathrm{MPa}$, respectively. Whereas, the split tensile strength increases from $3.18 \mathrm{MPa}$ to $3.37 \mathrm{MPa}$, for the corresponding percentage of fiber from 0 to $1.5 \%$, respectively. This reduction in compressive and even the low improvement in tensile strength could be attributed to the use of fiber as twisted fiber. This study will investigate the use of Aluminum strips as straight not as twisted from Coco-Cola waste cans to improve mechanical properties of mortar and concrete. All in all, the author conducted just one mix proportion and two tests which are compressive strength and tensile strength.

\section{Materials and Methods}

Having reported that other studies such as Murali et al., (2012) and Ravinder (2016), this study tries to be more comprehensive using 54 specimens for concrete and 63 specimens for mortar using waste Aluminum strips as reinforced concrete. Moreover, three types of mechanical properties, which are compressive strength, tensile strength and flexural strength, have been tested. Materials used in this study: ordinary Portland cement (Type I) [ASTM C 150], was used in all mixes, fine aggregate confirming Type F, was used in the study and confirming the British Standards-882(1992). Table 1 indicates the sieve analysis of fine aggre- 
gate and Table 2 demonstrates the sieve analysis of coarse aggregate with $10 \mathrm{~mm}$ maximum size.

Table 1: Sieve analysis of fine aggregates confirm with Type( F ) used in research.

\begin{tabular}{|l|l|l|}
\hline Sieve size & $\begin{array}{l}\% \text { Pass- } \\
\text { ing }\end{array}$ & $\begin{array}{l}\text { \% Passing by weight according to limits (BS- } \\
882,1992)\end{array}$ \\
\hline $10.00 \mathrm{~mm}$ & 100 & 100 \\
\hline $5.00 \mathrm{~mm}$ & 100 & 100 \\
\hline $2.36 \mathrm{~mm}$ & 93.9 & $80-100$ \\
\hline $1.18 \mathrm{~mm}$ & 84.1 & $70-100$ \\
\hline $\begin{array}{l}600 \quad \mathrm{mi}- \\
\text { cron }\end{array}$ & 90.0 & $55-100$ \\
\hline $\begin{array}{l}300 \mathrm{mi}- \\
\text { cron }\end{array}$ & 8.9 & $5-70$ \\
\hline $\begin{array}{l}150 \quad \mathrm{mi}- \\
\text { cron }\end{array}$ & - & - \\
\hline
\end{tabular}

Table 2: Grading of coarse aggregates used in the study with $10 \mathrm{~mm}$ maximum size.

\begin{tabular}{|l|l|l|}
\hline Sieve size & \% Passing by mass & \% Passing limits (B-S/882) \\
\hline $20.0 \mathrm{~mm}$ & 100 & 100 \\
\hline $14.0 \mathrm{~mm}$ & 100 & 100 \\
\hline $10.0 \mathrm{~mm}$ & 94.1 & $85-100$ \\
\hline $5.0 \mathrm{~mm}$ & 19.5 & $0-25$ \\
\hline $2.36 \mathrm{~mm}$ & 1.7 & $0-5$ \\
\hline
\end{tabular}

\section{Mix Proportions}

Using 1:1.75:3.6 (cement: sand:(crushed gravel) and w/c is 0.45 . For cement-sand mortar, the mix proportion was indicated in Table 3. Using Aluminum strips from Coca-Cola cans and which was cut to average dimensions of $1 \mathrm{~cm}$ width and $2 \mathrm{~cm}$ length as shown in Fig. 1. These strips were used as percentages by volume of concrete and mortar. The mechanical properties of Aluminum are indicated in Table 4. The Aluminum strips have been used with different ratios ranging from $0 \%$ to $2.5 \%$ with $0.5 \%$ increment for concrete; whereas, these ratios are from $0 \%$ to $3 \%$ for mortar.

Table 3: Ingredients of cement sand mortar used for each 1 cubic meter.

\begin{tabular}{|l|l|l|}
\hline Cement & Sand & Water \\
\hline $460 \mathrm{~kg}$ & $1340 \mathrm{~kg}$ & $210 \mathrm{~kg}$ \\
\hline
\end{tabular}

Table 4: Mechanical properties of Aluminum strips used in the study(Kaufman, 2000)

\begin{tabular}{|c|c|c|c|}
\hline Density & Tensile strength & $\begin{array}{c}\text { Modulus of } \\
\text { elasticity }\end{array}$ & $\begin{array}{c}\text { Elongation after } \\
\text { tensile test }\end{array}$ \\
\hline $\begin{array}{c}2700 \mathrm{~kg} \text { per } \\
\text { cubic meter }\end{array}$ & $\begin{array}{c}310 \mathrm{MPa} \text { (ulti- } \\
\text { mate) and } \\
276 \\
\mathrm{MPa}(\mathrm{yield})\end{array}$ & $70 \mathrm{GPa}$ & $12 \%$ at break \\
\end{tabular}

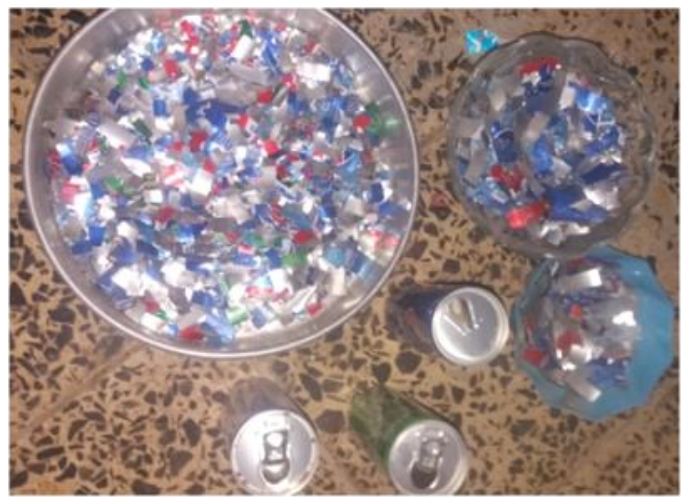

Fig. 1: Aluminum strips used in the study.

\section{Tests}

To conduct the tests, 54 specimens were for concrete and 63 specimens for mortar. Compressive strength test for concrete, cubes with $10 * 10 * 10 \mathrm{~cm}$ were used and took the average value for compressive strength at 28 days with curing. Tensile strength test done by using indirect method (splitting test for cylinders), and flexural strength done by using beams with $10 * 10 * 40 \mathrm{~cm}$ and tested after 28 days for finding flexural strength (modulus of rupture), the flexural test done by using the third point loading according to British standards 1881 [British Standards, 1983]. Whereas, the flexural test for mortar is done according to ASTM C348-86. Fig. 2 and Fig. 3 show beam under testing for flexural strength, and beams after testing (showing how the ductile failure occurs in Aluminum strips concrete.

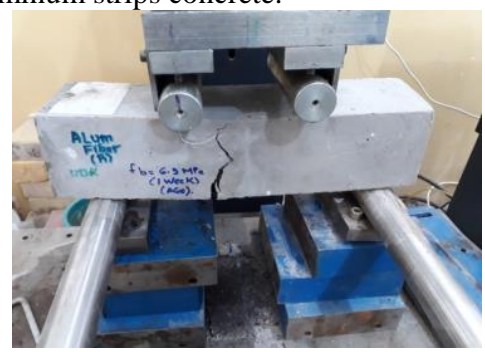

Fig. 2: Aluminum strip concrete beam under testing for flexural strength.

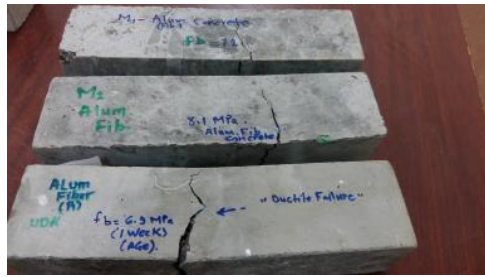

Fig. 3: Aluminum strip reinforced concrete Beams after the flexural test

\section{Results and Discussions}

Figures 4, 5 and 6 show the all the results in this study.

Firstly, the results of concrete will be stated. Fig. 4 shows the influence of different percentage of Aluminum strips on the compressive strength for concrete. The compressive strength increases slightly by adding more Aluminum strips up to the maximum value of $2.5 \%$. These strips lead to increment of about $22 \%$. This could be attributed by the action of strips that decrease the propagation of cracks under loading and delay failure so the specimen can absorb more values of loads. On the other hand, the tensile strength for concrete mixes highly increases from $1.87 \mathrm{MPa}$ at reference mixes to $5.38 \mathrm{MPa}$ (about $187 \%$ of increment) as indicated in Fig. 5 by adding maximum value of Aluminum strips. The flexural strength increased very highly from 3.31 MPa for reference mixes to $11.2 \mathrm{MPa}$ (about 238\%), as demonstrated in Fig. 6, for maximum value of Aluminum strips, it should be noted that the increment in mechanical properties after $2 \%$ fibers is very low, so the use of extra values of Aluminum strips is not important.

Secondly, the behavior of mortar improves with Aluminum strips than ordinary mortar. The compressive strength increased from $31.4 \mathrm{MPa}$ to about $40 \mathrm{MPa}$ (about $27 \%$ of increment) at $2.5 \%$ of Aluminum strips as indicated in Fig. 4. For tensile strength, there is an increment from 1.3MPa to $5.07 \mathrm{MPa}$ (about $293 \%$ of increment) at $3 \%$ of Aluminum strips as demonstrated in Fig. 5. Finally, the flexural strength for reinforced mortar with Aluminum mortar increased highly from $2.5 \mathrm{MPa}$ to $9.9 \mathrm{MPa}(296 \%)$ at $3 \%$ of Aluminum strips. The increment in compressive strength in this research can be attributed to the action of strips that make the concrete matrix stronger and delay cracks under loading (Tanoli and Fazli, 2014) so the specimen can resist more increased loads. 


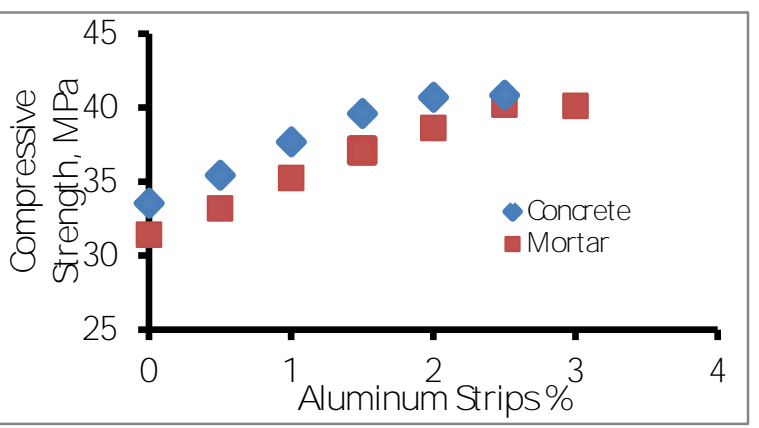

Fig. 4: Effect of Aluminum strip\% on the compressive strength for both concrete and mortar mixes.

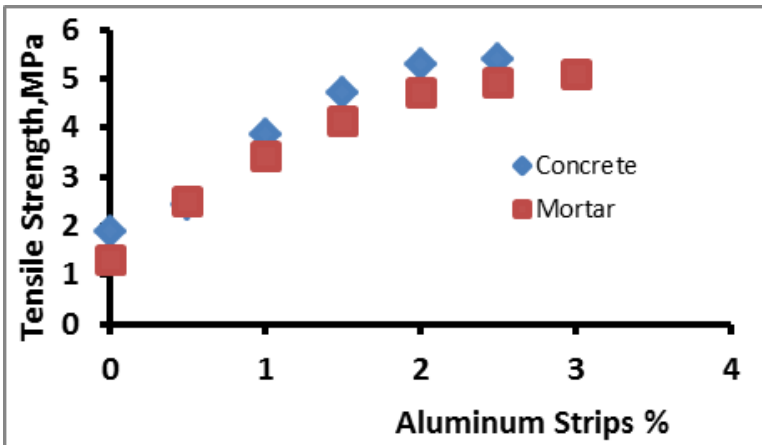

Fig. 5: Effect of Aluminum strip\% on the tensile strength for both concrete and mortar mixes.

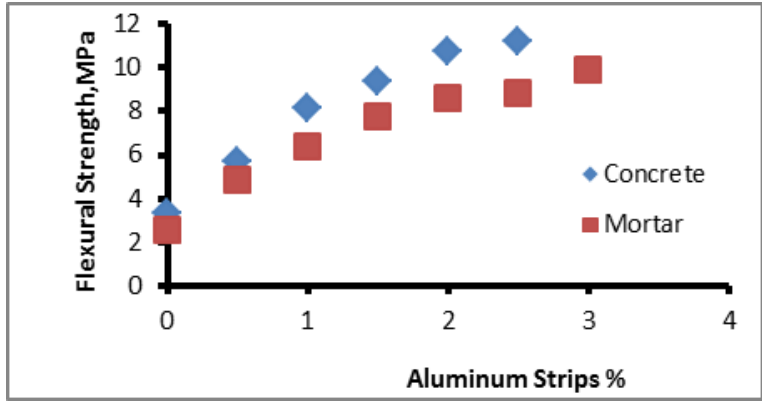

Fig. 6: Effect of Aluminum strip\% on the flexural strength for both concrete and mortar mixes.

The flexural strength is highly increased in concrete and mortars, this can attribute to two reasons, first is about the high tensile strength of Aluminum strips which is $310 \mathrm{MPa}$, and secondly is the action of strips that give extra bonds with concrete and make concrete more strong and reduce the propagation of cracks during loading (Ravindra and Mishra, 2011; and Martius-Hammer, 2015), also the failure of specimens especially in flexural test is ductile (see Fig. 3), so the specimen not broke in two pieces, so the conclusion from that, is the action of Aluminum strips that gives more ductility to concrete and more toughness.

\section{Conclusions}

The main conclusions come up with this study could be summarized as:

This study reveals that using Aluminum strips which increases the compressive strength of concrete up to $22 \%$ with $2.5 \%$ of Aluminum strip comparing with the reference mix.

The value of tensile strength for concrete has been increased from $1.87 \mathrm{MPa}$ for a reference mix to $5.38 \mathrm{MPa}$ for $2.5 \%$ Aluminum strips. Whereas, the flexural strength (modulus of rupture) of concrete increases significantly from $3.31 \mathrm{MPa}$ for a reference mix to 11.20 MPa for $2.5 \%$ Aluminum fiber.
The compressive strength for mortar also increases by $28 \%$ at $2.5 \%$ of Aluminum strips which higher than the corresponding value as mentioned above in Point 1.

The tensile and flexural strengths for mortar have also increased from $1.29,2.56 \mathrm{MPa}$ to 5.07 and 9.90 at $3 \%$ Aluminum strips, respectively.

This study indicates that using Aluminum as the straight strip is better than twisted strips as used by other studies.

\section{Acknowledgment}

The authors would like to thank the staff in the Lab of Civil Engineering Department/University of Kufa for their supports in this study.

\section{References}

[1] Portland Cement. American Society for Testing and Materials. CFR Section(s): 30 CFR 250.901(d) (9).

[2] ASTM C348-86. (1989). Standard Test Method for Flexural Strength of Hydraulic Cement Mortars. Annual Book of ASTM Standard, 4(1), 204-209.

[3] British Standards Institution. (1983). Testing concrete: Method for determination of flexural strength. British Standards Institution.

[4] Kaufman, J. G. (2000). Introduction to aluminum alloys and tempers. ASM international.

[5] Martius-Hammer, T. A. (2015). COIN-Final report.

[6] Milind, V. (2016). Innovative Use of Steel Fibers in Rigid Pavements. International Conference on Science and Technology for Sustainable Development (ICS SD), 73-79.

[7] Murali, G., Vardhan, C. V., Prabu, R., Khan, Z. M. S. A., Mohamed, T. A., \& Suresh, T. (2012). Experimental investigation on fibre reinforced concrete using waste materials. International Journal of Engineering Research and Applications (IJERA) ISSN, 2248, 27

[8] Ravinder, K. (2016). Strength characteristics of coca-cola tin waste as fibres in concrete. Int. J. Adv. Res. Found, 3(2),9-12.

[9] Ravindra, V. S., Mishra, C. B., Umrigar, F. S., \& Sinha, D. A. (2011). Use of Steel Fiber in Concrete Pavement: A Review. In National Conference on Recent Trends in Engineering \& Technology.

[10] Standard, B. 882: 1992. 'Specification For Aggregates From Natural Sources For Concrete'. British Standard, 1-9.

[11] Tanoli, W. A., Naseer, A. M. J. A. D., \& Wahab, F. A. Z. L. I (2014). Effect of Steel Fibers on Compressive and Tensile Strength of Concrete. International Journal of Advanced Structures and Geotechnical Engineering, 3(4), 393-397.

[12] Wafa, F. F. (1990). Properties \& applications of fiber reinforced concrete. Engineering Sciences, 2(1).

[13] WARP. (2010). Material Change for a Better Environment. Case Studies (see::http://www.wrapcomplaince.org/) 